
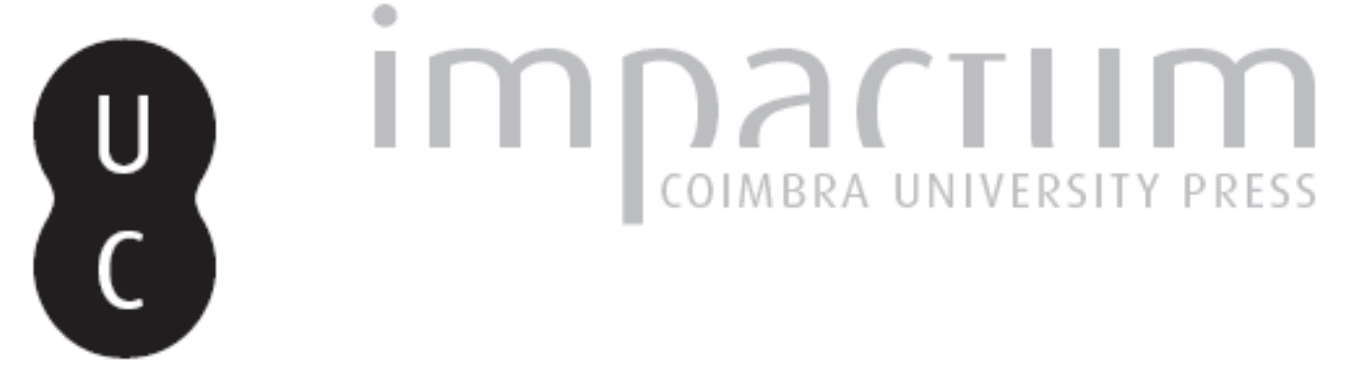

\title{
A espacialização dos insumos no turismo: proposta de uma leitura metodológica aplicada aos fluxos nos casos de Coimbra e Figueira da Foz, em Portugal
}

Autor(es): $\quad$ Furtado, Edna; Cravidão, Fernanda

Publicado por: Imprensa da Universidade de Coimbra

URL persistente:

URl:http://hdl.handle.net/10316.2/36891

DOI:

DOI:http://dx.doi.org/10.14195/0871-1623_33_11

Accessed : $\quad$ 26-Apr-2023 07:46:29

A navegação consulta e descarregamento dos títulos inseridos nas Bibliotecas Digitais UC Digitalis, UC Pombalina e UC Impactum, pressupõem a aceitação plena e sem reservas dos Termos e Condições de Uso destas Bibliotecas Digitais, disponíveis em https://digitalis.uc.pt/pt-pt/termos.

Conforme exposto nos referidos Termos e Condições de Uso, o descarregamento de títulos de acesso restrito requer uma licença válida de autorização devendo o utilizador aceder ao(s) documento(s) a partir de um endereço de IP da instituição detentora da supramencionada licença.

Ao utilizador é apenas permitido o descarregamento para uso pessoal, pelo que o emprego do(s) título(s) descarregado(s) para outro fim, designadamente comercial, carece de autorização do respetivo autor ou editor da obra.

Na medida em que todas as obras da UC Digitalis se encontram protegidas pelo Código do Direito de Autor e Direitos Conexos e demais legislação aplicável, toda a cópia, parcial ou total, deste documento, nos casos em que é legalmente admitida, deverá conter ou fazer-se acompanhar por este aviso.

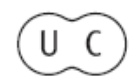




\section{Cadernos de Geografia}
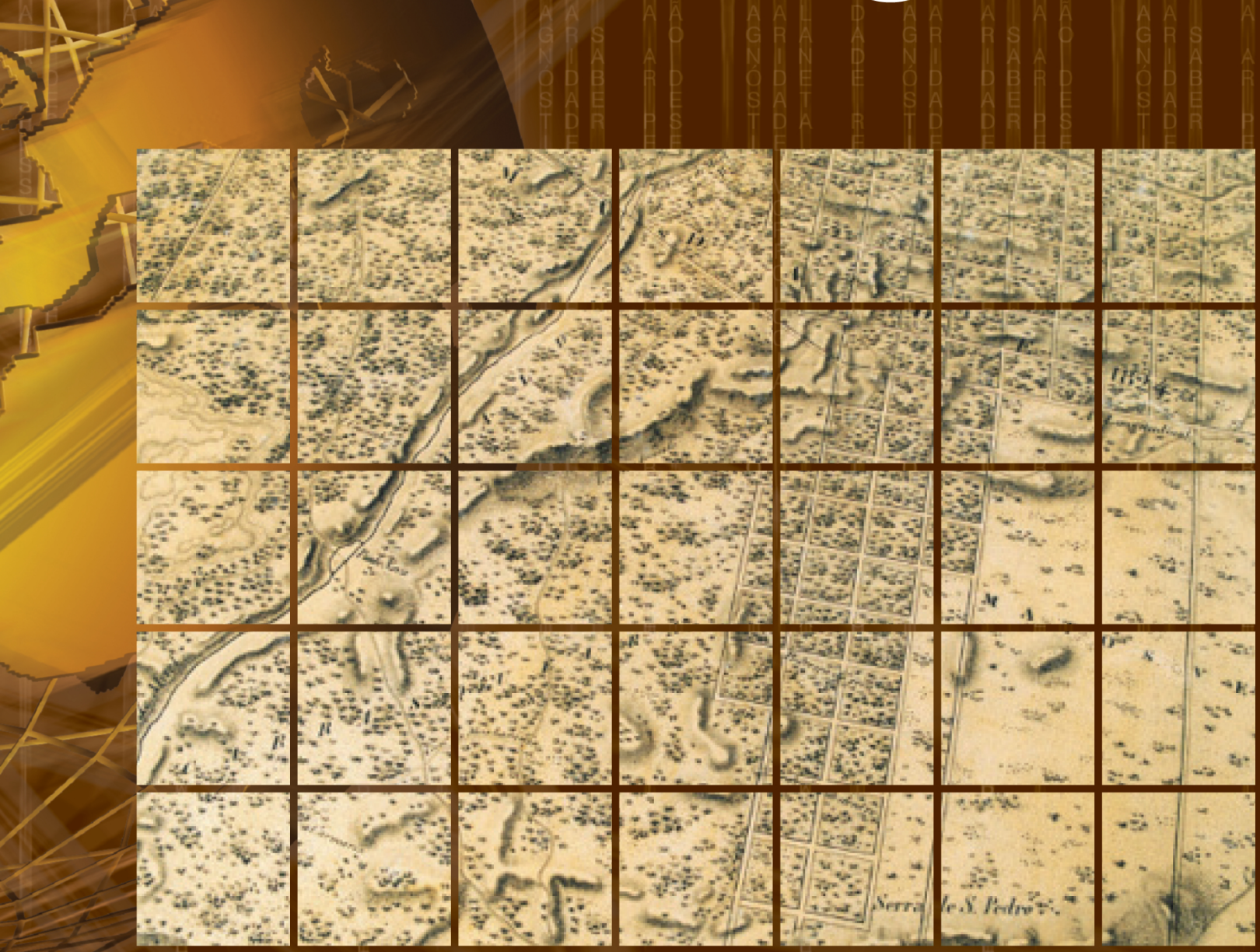

№ 33 - 2014

Imprensa da Universidade de Coimbra Faculdade de Letras | Universidade de Coimbra 


\title{
A espacialização dos insumos no turismo: proposta de uma leitura metodológica aplicada aos fluxos nos casos de Coimbra e Figueira da Foz, em Portugal The spacialization of commodities in the tourism: proposal of a methodology applied to flows in case Coimbra and Figueira da Foz - Portugal.
}

\author{
Edna Furtado \\ Departamento de Geografia. Universidade Federal do Rio Grande do Norte. \\ ed.furtado@hotmail.com
}

\section{Fernanda Cravidão}

Departamento de Geografia. Faculdade de Letras. Universidade de Coimbra. cravidao@fl.uc.pt

\section{Resumo:}

Os estudos realizados pela Geografia tendo o turismo como objeto, sempre têm ficado restritos aos efeitos resultantes da atividade, quando da sua realização, sem considerar que, por de trás desse "acontecer”, existe um conjunto de atividades que oferecem suporte à permanência do viajante no local visitado. A pesquisa em tela procurou explorar e conhecer quais são, onde e quando se realizam trocas de natureza diversificada, que oferecerão suporte à atividade turística. Assim, o artigo tem por objetivo apresentar uma proposta de metodologia de espacialização dos fluxos de insumos, que sustentam a atividade turística em Coimbra/Portugal, utilizando-se de uma matriz interdisciplinar. Os resultados da pesquisa identificaram e analisaram como os espaços da hinterlândia dessa localidade respondem à demanda por insumos ao receptivo local, especificamente daqueles estabelecimentos hoteleiros de maior envergadura. 0 mapeamento possibilitou verificar como se distribuem os fluxos de insumos e qual a intensidade dessas relações espaciais.

Palavras-chave: Turismo. Espacialização de insumos. Coimbra.

\section{Abstract:}

The geographic studies which has tourism as the object of study has always been restricted to the effects resultant of the activity, without considering that behind this "happening" there is a set of activities that support the tourists' stay. The presented research seeks to explore and to know what, where, and when exchanges of commodities that will offer support to tourism the demand for commodities of the reception site, specifically where there are large scale hotel companies. The mapping has also permitted to verify how the goods' flows are distributed and what the intensity of these spatial relationships are.occur.Therefore, the paper aims to propose one spatialization's methodology of flows of goods that support tourism in Coimbra - Portugal, using an array of disciplines. The survey results have both identified and analyzed how the hinterland spaces of these areas responded to.

Keywords: Tourism. Commodities spatialization. Coimbra. 


\section{Notas introdutórias}

O debate em torno do desenvolvimento, seja qual for sua adjetivação, tem sido alvo de discussões e posicionamentos quase sempre divergentes entre teóricos das mais diversas áreas do conhecimento. Atualmente os processos de desenvolvimento têm-se viabilizado (ou restringido) em face de um conjunto de acontecimentos e políticas que acabam produzindo efeitos diferenciados no espaço. Essas políticas e acontecimentos podem muitas vezes adquirir centralidade no processo de desenvolvimento dos lugares, a exemplo daquelas iniciativas que tratam de turismo como um vetor de dinamismo socioeconômico.

Embora a geografia já apresente uma produção significativa sobre o turismo, tem faltado uma abordagem mais verticalizada do alcance sócio-espacial desses efeitos; ou seja, investigações que tratem dos fluxos que sustentam a atividade, os quais muitas vezes passam ao largo do "olhar" do visitante e dos estudos académicos.

Adicionalmente, a literatura que trata do turismo está bastante matizada pelo viés económico e sustenta sua argumentação nos chamados efeitos multiplicadores e seus transbordamentos. Esse debate merece um olhar mais acurado a fim de evidenciar distintas realidades rondando os pólos turísticos e que nem sempre tais efeitos são possíveis e nem ocorrem com a intensidade tão propalada.

Assim, o presente artigo procura demonstrar até que ponto a atividade turística tem contribuído para efetivar o desenvolvimento das suas áreas de entorno, através do transbordamento dos fluxos de insumos que sustentam a atividade.

Trata-se da ampliação de uma pesquisa realizada em Natal-RN e que agora se debruça sobre as localidades de Coimbra/Figueira da Foz - Portugal, que procura elucidar questões tais como: Até onde vão os fluxos de insumos que sustentam o turismo nessas localidades? Que razões levam o parque hoteleiro a optar por determinados fornecedores, com distintas localizações? Quem são os fornecedores desses insumos, de forma direta e indireta? Qual a magnitude do pólo turístico na geração de postos de trabalho e qual a qualidade desses empregos? Que contribuição à geografia se faz a partir de uma metodologia como essa? Quais as contribuições que um estudo dessa natureza pode oferecer na formulação de políticas públicas?

O valor desta pesquisa está, pois, essencialmente atrelado à compreensão das relações socioespaciais estabelecidas por meio do Turismo praticado em Coimbra/Figueira da Foz - Portugal. Para tanto, entende-se a espacialização dos fluxos que sustentam essa economia como um importante recurso de análise, buscando respostas para as questões anteriores. Trata-se de uma primeira investida no território português e um olhar aperfeiçoado da pesquisa que se desenvolveu em Natal. Não se pretende dar respostas a todas as questões suscitadas acima, apenas indicar quais caminhos a pesquisa está tomando nessa sua fase intermediária.
0 artigo se estrutura a partir de um debate teórico que procura alcançar categorias necessárias ao entendimento do problema: na sequência, faz uma breve caracterização das áreas estudadas, apontando suas particularidades, em seguida expõe, de forma breve, a metodologia que norteia o estudo, para então discutir os resultados e apresentar as análises mostrando onde há aproximações e diferenciações nos casos estudados, e finalmente trazer mais alguns pontos de inquietação que possibilitarão a continuidade do debate.

\section{O uso do espaço pelo (e para) o turismo: apontamentos concetuais}

O turismo envolve uma série de fatores e elementos geradores de algumas dinâmicas pouco exploradas, que está por trás do momento da viagem, que sustenta a economia turística por intermédio do seu conjunto de insumos.

Esse amplo espectro de "necessidades" permite inferir que o turismo resulta de uma série de fatores, e que esses fatores possuem traços espaciais, que pré existem e se mantém e enquanto outros são modificados com a sua chegada, principalmente no que se refere à quantidade e qualidade dos insumos necessários ao momento da viagem.

No debate sobre o turismo é importante ressaltar que, diante do contexto económico atual, a atividade adquiriu espaço crescente. Isso em parte se deve ao seu efeito multiplicador - defendido por alguns teóricos como Beni (1998) ou Oliveira (2001) - envolvendo uma complexa cadeia de outras atividades que dá o suporte necessário ao seu acontecimento. Nesse sentido é importante destacar o conceito de efeito multiplicado trazido por Silva: "A noção do multiplicador relacionada à atividade turística corresponde a um conceito simples e de fácil verificação na realidade. 0 dinheiro deixado pelo turista, pelo pagamento do hotel e da estada, por exemplo, tende a passar pelos diversos setores da economia. Esta primitiva despesa não fica nas mãos do hoteleiro ou do dono do restaurante que a recebe, sendo utilizada para pagamento dos vários bens e serviços necessários a estes últimos para assegurar os serviços requisitados pelo turista" (SILVA, 2004: 295).

A utilização desse conceito mostra-se fundamental ao debate teórico e a pesquisa aqui proposta, pois aclara o caminho percorrido pelos recursos deixados pelos visitantes e permite identificar essa cadeia que envolve o turismo, bem como a forma de ocorrência do efeito multiplicador e dos transbordamentos para os demais setores da economia.

Há também outros autores como Garcia (1998) e Etges (1998), que afirmam ser o turismo uma atividade associada historicamente ao desenvolvimento dos lugares onde se instala, sobretudo quando isso ocorre em áreas de economia deprimida. Ambos os aspectos estariam estreitamente relacionados entre si e se expressariam por meio da citação de Silva: "O produto turístico se realiza por intermédio de um 
conjunto de atividades e serviços [...] indústria das construções e indústria da transformação [...] atividade agrícola e indústria alimentícia [...] indústria de transformação e de consumo energético, além de serviços [...] artesanato e indústria do vestuário ou de transformação [...]" (SıLVA, 2004: 263).

Discutir o turismo como atividade econômica é certamente pensar sobre o pós-fordismo e sua consequência no desdobramento do terciário como efeito evolutivo dos serviços. Essa discussão implica, com certeza, o entendimento do rumo crescente, de forma espiralada, que tomaram os transportes na sociedade do segundo pós-guerra mundial, combinada com a extraordinária rapidez, no desenrolar da segunda metade do século $X X$ e início deste século, do meio técnico, científico e informacional, este ultimo subvertendo o conceito espaço-tempo, acelerando forma e conteúdo.

A ideia de viajar, experimentar, compartilhar "o sugerido", checar o marketing, tem se apresentado como um motivo pelo qual o turismo exerce um claro e intenso fascínio na sociedade pós-fordista: “[...] Entendendo o turismo como um produto é preciso criar modos de consumo que se ajustem a um conjunto de características dominantes como são: o aumento do poder de compra, a mobilidade acrescida, maior informação, mas também preferências mais voláteis e consumistas, ainda assim em contraponto com a sua capacidade de influenciar a oferta e a procura de identidade, que implica a segmentação do mercado [...]" (SAntos, 2012: 444).

A atividade constitui-se, dessa forma, em mais uma possibilidade de circulação de mercadoria, num desdobramento do capital em consonância com uma também renovada divisão territorial do trabalho. Nesse contexto, o tempo, e especialmente o espaço geográfico, resultado do amálgamar histórico, adquire status de objeto de consumo.

Geralmente as principais mudanças ocorridas na reestruturação do capital e que têm corroborado com a consolidação dessa nova divisão do trabalho encontra sustentação sobretudo na informação/telecomunicação e distribuição/transporte, que, segundo Diniz e Matos (2006), citando Santos (1993): "caracterizam a própria relação espaço-tempo dos fluxos, sejam eles de mercadorias ou de informações". Essas novas tecnologias possibilitam uma diminuição das distâncias, favorecendo a formação de redes e/ ou dos "territórios-rede". Pode-se observar que as condições criadas nesse processo de inovação de paradigma, oportunizaram a ampliação/diversificação de múltiplos segmentos do terciário, entre eles o turismo, que se vêm consolidando num contexto global/local, especialmente a partir das duas últimas décadas do século XX.

Assim, discutir o turismo como atividade econômica é certamente pensar sobre o desdobramento do terciário como efeito evolutivo dos serviços, com proeminência para as novas dinâmicas espaciais, construídas numa perspectiva de teia de informação/ comunicação, em um território cada vez mais instável, remodelado, reorganizado, servindo de apoio à reconfiguração do espaço. Nesse sentido, Cravidão aponta: "Tornou-se quase um lugar comum, fazer da atividade turística um dos principais caminhos para o desenvolvimento. [...] As regiões periféricas podem ter no turismo um meio inesgotável para promover a sua integração territorial; os centros urbanos podem, através do turismo, refuncionalizar-se, e ganhar as dinâmicas demográficas e econômicas há muito perdidas; as "velhas" áreas industriais encontram, no turismo, novos modos de se integrarem na economia, através, por exemplo, do seu patrimônio museológico, as paisagens ditas naturais ou em vias de extinção estão a transformar-se em verdadeiros santuários. Visitar o que ainda não desapareceu e que faz parte da história da Terra e do ser humano é um filão em crescimento [...]" (CRAVIDÃo, 2004: 310).

A atividade turística vem beneficiando desse novo momento, pois tanto na sua realização quanto na sua sustentação (antes, durante e depois da estada do visitante) se vale da informação e dos transportes. Os fluxos se tornam inerentes à atividade em função dos deslocamentos dos viajantes e de todo o aparato que viabiliza tanto a sua estadia quanto essas viagens. Nesse sentido, é importante resgatar Santos que pontua: "O espaço é, também e sempre, formado de fixos e fluxos. [...] cada tipo de fixo surge com suas características, que são técnicas e organizacionais. E desse modo a cada tipo de fixo corresponde uma tipologia de fluxos. Um objeto geográfico, um fixo, é um objeto técnico, mas também um objeto social, graças aos fluxos. Fixos e fluxos interagem e se alteram mutuamente" (SANTOS, 1996: 77-78).

No caso específico da atividade turística, entendida enquanto parte dessa totalidade que é o espaço, também vai estabelecer seus fluxos seguindo uma lógica de funcionamento particularizada e vai encontrar na rede hoteleira um importante motor dessas trocas. Assim, estabelecida a escala, o meio informacional remete, de forma crescente, a uma relação local/global, em que o "lucro" e as "trocas" se dão na conveniência de quem comanda a "venda" do lugar - mercadoria cada vez mais transformada em objeto de desejo pelo consumo de massa.

Existem muito mais aspectos subjetivos relacionados à produção dos lugares turísticos do que propriamente razões objetivas para que tais localidades sejam alçadas àposição de polos de atração de visitantes. O fato é que esses ciclos de "descoberta" e "descarte" dos espaços turistificados possuem tempos variados para ocorrerem, mas em geral as trajetórias de ascendência e decadência se dão em meio a uma forte competição dos espaços geográficos pelos fluxos de viajantes.

\section{Aproximações e distinções do turismo de Coimbra e Figueira da Foz}

Ao discutir os locais da pesquisa não se pode perder de vista um contexto mais geral que coloca o turismo de Portugal em posição privilegiada no cenário europeu conforme destacado por Sirgado: "O grande dinamismo recente do turismo em Portugal 
decorre, sobretudo, das características organizacionais que têm orientado o sector, num pano de fundo de uma utilização fortemente contrastada do território [...] as principais características são: 1) forte procura externa, em contraste com uma procura interna exígua e fortemente sazonal; 2) especialização relativa do produto sol, mar e praia; 3) concentração regional e local da oferta e da procura; 4) peso excessivo de ofertas paralelas de alojamento, com conseqüências notórias nos índices de preços praticados; 5) forte dependência das operadoras internacionais; 6) caracter de genuinidade dos atractivos naturais e culturais das regiões portuguesas" (SIRGADo, 1993: 25).

De forma sintética, pode-se afirmar que o turismo português viajantes estrangeiros, que possuem forte interesse na área litorânea e especificamente em determinadas localidades. Os dois casos estudados possuem aspectos relevantes que os aproximam, sobretudo quando se pensa no cenário nacional, mas os distanciam quando observados na perspectiva da segmentação do mercado.

0 turismo em Coimbra insere-se em um contexto marcado pela proximidade de grandes centros turísticos do continente europeu, conforme sinaliza Santos: "As cidades europeias são tesouros patrimoniais evoluindo durante vários séculos, crescendo num tempo longo. Essa evolução tem merecido, em Coimbra, uma atenção especial" (SANTOS, 2012: 442). Tal situação impõe à cidade estratégias de enfrentamento desiguais em face da presença constante na grande mídia especializada em viagens por partes desses grandes centros que continuam a se hegemonizar no cenário da atividade.

Apesar da presença de cidades renomadas mundialmente, como Paris, Londres, Veneza, Barcelona, Berlim, entre outras, Coimbra tem demarcado um espaço contando sua história, principalmente resgatando seu papel na resistência a governos de exceção, e tem na sua Universidade um marco dessa trajetória, agora expressa, também como Património Mundial da Unesco. Assim, embora possua um sítio histórico notável, parte do fascínio que a cidade desperta nos visitantes relaciona-se à instituição que permanece como principal ponto de parada para os turistas que visitam a cidade. Santos pontua essa relação ao dizer: "A cidade de Coimbra integra um projeto interessante, que tendo começado de uma situação de bulldozer urbano, como a construção do Polo I da Universidade, desde os anos de 1940, se transformou na valorização dos recursos patrimoniais existentes e na constituição de um produto com pertinência de sustentabilidade territorial e com capacidade de atração de visitantes, ao poder de vir a tornar-se num produto de excelência associado à relação "Univer(sc) idade", através da Candidatura da Universidade de Coimbra a Patrimônio Mundial da UNESCO" " (SANTOS, 2012: 439).

A confirmação daquilo que Santos aponta como uma possibilidade ainda é uma incógnita, pois não

Fato que veio a se efetivar em dezembro de 2012. se têm dados para mensurar os efeitos da entrada de Coimbra na lista de UNESCO. De toda forma, sabe-se que muitas localidades, sejam históricas ou naturais, tiram proveito dessa titulação para promover o turismo e ampliar sua visibilidade. Fato que fica claro também quando Santos diz: “Este projeto é simultaneamente um "produto turístico, vendável a uma sociedade cada vez mais competitiva globalmente, sendo um meio para atingir um fim, ou seja, uma forma que as cidades históricas descobriram para minorar os efeitos da sua perda de competitividade ou, por outro lado, uma forma de maximizar o seu potencial turístico" (CUCPU), como uma estratégia de marketing que, eventualmente, permite alguma preocupação com o patrimônio e com os costumes, tradições e saber-fazer da população que aí habita" (SAntos, 2012: 439).

Há um conjunto de intencionalidades expressas e tácitas por trás desse título de Patrimônio da Humanidade. A Universidade confirma sua centralidade no roteiro turístico local e contribui para integrar Coimbra, definitivamente, no cenário nacional da atividade. Uma pesquisa de caracterização do turismo em Coimbra, realizada em 2007, apontou que 32\% dos visitantes tinham por motivação a sua visita.

No caso especifico de Figueira da Foz, apesar de sua visibilidade regional e nacional, sua trajetória de cidade balneária se inicia tardiamente, assim como todas as demais áreas urbanas litorâneas de Portugal, conforme aponta Nunes: “A prática balnear junto ao mar é um fenómeno tardio em Portugal, quando comparado com outros países europeus. Pode ser detectado após a implantação do liberalismo e anunciado pelo despontar de "novos gostos e diferentes hábitos de sociabilidade" no seio da emergente burguesia liberal" (NunEs, 2009: 60).

0 autor mostra que as localidades balneares não surgem de forma espontânea, são uma resposta a um movimento maior que desloca as áreas de interesse turístico, assim como continuam a fazer até hoje. Nesse sentido, destaca: "Assiste-se em Portugal, nas últimas décadas do século XIX, à alteração desses "lugares de distinção" restritos às práticas de lazer entre as elites. As zonas termais e quintas, nos arredores dos centros urbanos, locais predominantemente consignados ao lazer, são paulatinamente substituídas pelas zonas da beira-mar, junto do litoral" (Nunes, 2009: 62).

E prossegue sua analise situando Figueira da Foz em um contexto que privilegiou áreas mais densamente povoadas no surgimento dessas atividades voltadas para o lazer, e destaca que parte do litoral português compreendido entre a foz do rio Douro e a do Mondego possuía essas características, relatando assim haver: "[...] conjuntura indiciadora de uma política de excessiva concentração no litoral dos principais factores de desenvolvimento económico, e da aposta num turismo excessivamente vocacionado para o aproveitamento de dois recursos naturais e abundantes: sol e mar" (NunEs, 2009: 63).

Dessa forma, a Figueira da Foz foi reunindo condições para se consolidar como uma das principais áreas voltadas ao turismo de praia exercendo 
forte atração, sobretudo na porção meio norte do litoral português, uma vez que a maior parte de suas concorrentes encontra-se no sul ou nas proximidades de Lisboa.

Os fluxos que já em 1870 contabilizavam 20 mil viajantes e em 1900 chegava aos 30 mil, segundo Nunes (2009), mantiveram-se ao longo do tempo e acentuaram-se com a presença do Casino da Figueira da Foz, para onde acorriam turistas de diversas partes da Europa, principalmente da Espanha. Nunes pontua essas marcas do turismo de Figueira da Foz ao dizer que o local: “[...] para além do desfrute da beira-mar e do jogo, privilegiem uma forte relação com outras componentes do lazer, apostando no acesso rápido a zonas turísticas limítrofes, procurando diversificar a oferta turística local, eis o que nos parece na época uma aposta moderna e audaz" (NunEs, 2009: 105).

Isso se refletiu no seu parque hoteleiro, marcado pela diversidade de estabelecimentos, tanto na sua natureza como no tamanho, merecendo destaque o Grande Hotel de Figueira da Foz, atualmente modernizado e vinculado a uma cadeia internacional.

É interessante destacar que o trabalho de Nunes (2009) entende a Figueira da Foz e Coimbra como partes de um espaço maior que reúne outras localidades com atributos turísticos diversos e que, portanto, formariam um circuito marcado pela heterogeneidade de paisagens naturais e culturais, conforme se depreende de seu texto: "Apoiada numa visão que actualmente poderemos definir como estratégica, na qual cidade surge como pólo difusor de visitantes/turistas incluída no "triângulo Coimbra-Figueira-Bussaco”, e outros locais históricos próximos, como Leiria, a cerca de "duas horas de viagem" onde se destaca a visita do "vetusto castello", a Batalha, com a possibilidade de "admirar o mosteiro, imponente e maravilhoso monumento de architectura gótica. Pantheon dos reis da segunda dynastia" (Nunes, 2009: 105).

As duas localidades objeto desta pesquisa, apesar de apresentarem características diversas, podem ser entendidas como parte de um espaço que reúne fluxos de viajantes com interesses diversos e, portanto segmentados do ponto de vista social, como também daquilo que desejam desfrutar nos seus deslocamentos.

\section{Abordagem metodológica}

Para o desenvolvimento do presente estudo foram utilizados os seguintes procedimentos metodológicos: consulta em obras de geografia, economia, sociologia, entre outras ciências, que formam referencial teórico necessário ao entendimento do turismo na atualidade.

A sua realização contribui para constituição de uma metodologia que não se limite ao debate dos efeitos multiplicadores do turismo no âmbito dos demais setores económicos, e ultrapasse essa visão, analisando até onde esses efeitos alcançam do ponto de vista espacial.
No Distrito Federal - Brasil foi desenvolvida uma pesquisa que teve como pano de fundo o debate sobre os efeitos multiplicadores da atividade turística na economia, tomando como base a segmentação adotada pelo estudo em tela. No entanto, os agrupamentos dividiram-se somente em Distrito Federal e Outras Unidades da Federação, sem detalhar a origem. Da mesma forma os produtos também ficaram agrupados pelos setores primário e secundário, sem maior aprofundamento.

Mas o referido estudo traz importantes pontuações ao tratar da relação entre a atividade turística e o processo de desenvolvimento ao comentar que: "A teoria dos pólos de crescimento sugere a necessidade de introduzir nas regiões a serem desenvolvidas setores que tenham ligações de insumo-produto por meio de compras e vendas de insumos. O pólo de crescimento surgirá quando esses setores aglomerados em determinada região ou localidade provocarem transformações estruturais e expandirem o produto e o emprego onde estão inseridos" (UNIVERSIDADE DE BRASíLIA/CET, 2008: 67).

Nesse sentido se verifica no fragmento textual aspectos que dialogam com o presente estudo. Em primeiro lugar, o debate sobre a relação entre o turismo e o desenvolvimento, onde as localidades turísticas são vistas como consumidoras de insumos e capazes de garantir transbordamentos espaciais, tornando-se polos que irradiam efeitos económicos da atividade, inclusive como áreas de atração de recursos humanos.

Outro aspecto que merece ser ressaltado na pesquisa elaborada no Distrito Federal reside no pressuposto que as relações de compra e venda entre os setores fortalecem a geração de emprego e renda e desenvolvem a região como um todo. Isso se daria em face dos encadeamentos (linkages) para trás ou para frente que, em tese, beneficiam outros setores com demanda pelos seus produtos ou oferecendo os insumos necessários para sustentar outros processos produtivos.

Não resta dúvida que há uma forte articulação entre os muitos setores produtivos que sustentam o turismo e que seus efeitos são amplos, atingindo diversas atividades. No entanto, esses efeitos nem sempre se espraiam espacialmente, causando transformações relevantes nas áreas adjacentes, ficando quase sempre muito localizadas no próprio polo turístico, principalmente quando trata-se de uma cidade de porte médio ou grande que já possui boa parte daquilo que é necessário à atividade. A pesquisa realizada no Distrito Federal alerta para essa questão: “[...] Ocorre, porem, que a atração de indústrias e setores que buscam obter um pólo de crescimento pode ser frustrada quando as relações de insumo-produto ou os efeitos de encadeamento não se dão majoritariamente na região ou na localidade que se quer desenvolver. Neste caso, a renda gerada pela compra ou pela venda de insumos acaba vazando para o exterior da região ou do país, deixando de beneficiá-los" (UNIVERSIDAde DE BRASílIA / CET, 2008: 67). 
Merece ser ressaltado que a pesquisa realizada em Natal já se encontra em estágio avançado com dados tabulados e analisados, pois se desenvolve desde 2008 e contou com uma fase de campo na qual foram pesquisados todos os estabelecimentos hoteleiros da principal área turistificada da capital potiguar - o bairro de Ponta Negra -, dos maiores até às pequenas pousadas, passando por estabelecimentos de porte mediano.

De forma similar à pesquisa realizada em Natal, foram realizadas visitas aos estabelecimentos hoteleiros para aplicação de questionários e entrevistas nos hotéis da área central de Coimbra e Figueira da Foz, bem como aos distribuidores desses insumos, com aplicação de questionários e formulários, por finalidade compreender a lógica espacial dos fluxos construídos nesse processo de abastecimento. Nas duas localidades estudadas foram escolhidos quatro estabelecimentos hoteleiros que atendem segmentos diferenciados de viajantes e se apresentam entre aqueles de maior expressão.

Nos questionários são feitas perguntas detalhadas quanto à origem geográfica dos produtos e à frequência de aquisição/abastecimento; em relação à força de trabalho, procura-se saber a origem e o cargo dos empregados, o número de pessoas em cada um desses cargos, a natureza da relação trabalhista (subcontratado, terceirizado, empregado formal) e a qualificação desses trabalhadores; nos estabelecimentos hoteleiros que possuem restaurantes independentes, o questionário foi igualmente aplicado para identificar a origem dos insumos e o perfil dos trabalhadores.

Há um corte setorial e espacial. Em relação ao primeiro, é importante destacar as relações estabelecidas pelo setor hoteleiro, objeto do estudo. Apesar do foco da pesquisa, a metodologia construída também pode se aplicar a outras atividades que lidam diretamente com os visitantes, como restaurantes, locadoras de automóveis, entre outros.

0 estudo além de mensurar os insumos, onde se inclui a força de trabalho, também procura dimensioná-los no espaço geográfico. Assim, a apresentação dos dados se dará na forma de gráficos ou através de mapas e cartogramas. Pretende-se que a realidade encontrada possibilite analisar e cotejar essas informações para verificar similitudes ou diferenciações em relação aos maiores estabelecimentos.

\section{Os fluxos: outras sinalizações do que os aproxima e os distancia}

A intenção maior dessa parte do estudo é evidenciar as possibilidades metodológicas ainda pouco exploradas para compreender fluxos em determinadas atividades econômicas e sua lógica espacial.

Os resultados da pesquisa revelam aspectos diferenciados em relação a cada conjunto de insumos. No que se refere a origem da mão de obra empregada nos estabelecimentos de Coimbra e Figueira da Foz, verifica-se a concentração de trabalhadores originários da área central e do norte de Portugal.

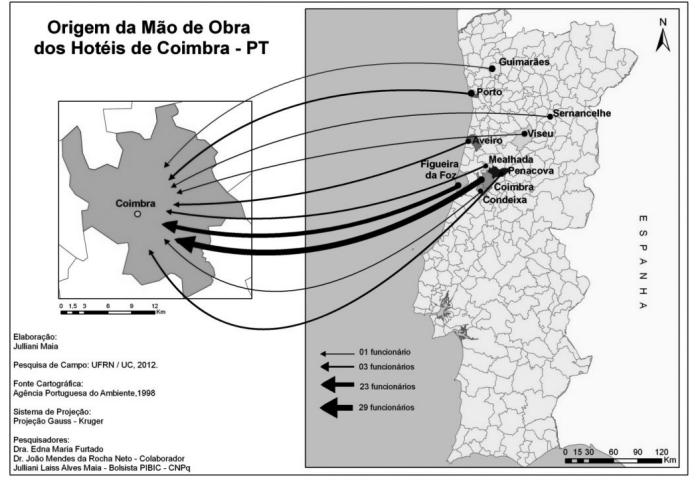

Figura 1

Origem da mão de obra para os hotéis de Coimbra e Figueira da Foz Fonte: Pesquisa de campo, 2013.

Diferentemente de Natal, Coimbra/Figueira da Foz emprega trabalhadores locais nos postos mais altos do estabelecimento. Percebeu-se um alto nível de qualificação dos profissionais, como parte de uma política de RH das grandes cadeias onde atuam: além das habilidades que trazem de sua formação, também desenvolvem outras ao longo do exercicio profissional, passando por unidades de tamanho e importância diferenciadas no âmbito interno da rede hoteleira à qual se vinculam.

Em Figueira da Foz, evidencia-se uma relação de trabalho peculiar. Por se tratar de um estabelecimento fortemente sujeito à sazonalidade, há um reduzido staff que se vincula ao hotel e uma expressiva mão de obra que é contratada via terceirização todas as vezes que o estabelecimento tem sua ocupação ampliada, seja por eventos empresariais/científicos ou por acontecimentos festivos que se utilizam das instalações do hotel.

0 recurso da terceirização/subcontratação de mão de obra é amplamente discutido por sociólogos e economistas que se debruçam sobre os efeitos do capital globalizado frente ao mundo do trabalho e investigam as estratégias utilizadas pelas grandes corporações, merecendo destaque esses recursos que desvinculam os empregados das relações formais com a organização.

No caso de Coimbra/Figueira da Foz, há algumas semelhanças com Natal, mas também há características de distinção: os mapas mostram diversidade desses fluxos, mas também sinalizam para lógicas distintas quando considerados produtos alimentícios industrializados e outros relativos a higiene e limpeza, apontando para predominância dos estabelecimentos atacadistas localizados nos maiores centros urbanos - Lisboa, Porto e mesmo Coimbra.

Quando se considera o subgrupo de alimentos tradicionais que passam por algum processo de industrialização, as origens ampliam-se para localidades menores. 


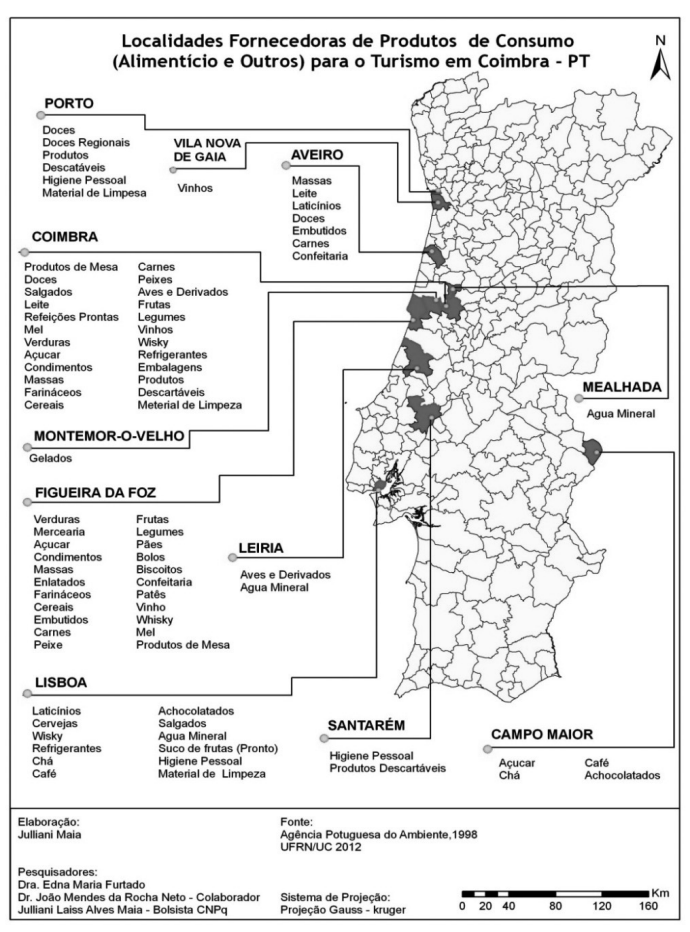

Figura 2

Localidades fornecedoras de produtos para os hoteis de Coimbra e Figueira da Foz

Fonte: Pesquisa de campo, 2013.

O ponto que aproxima é a relação existente entre os estabelecimentos hoteleiros e os grandes atacadistas. No caso de Coimbra/Figueira da Foz se verificou a forte dependência de duas grandes redes, uma delas mundial, que fornecem grande parte daquilo que é consumido pelos hotéis.

As poucas exceções a essa intermediação ocorrem com a aquisição de produtos característicos de Portugal, como vinhos, doces e laticínios, adquiridos em caves ou nos estabelecimentos tradicionalmente conhecidos pela fabricação artesanal dos mesmos.

Nas duas localidades fica evidente que o preço que se pratica para esses grandes estabelecimentos torna-se determinante para a preferência de aquisição dos insumos junto dos atacadistas. Isso se potencializa quando aliado ao padrão de qualidade requerido por esses hotéis, principalmente dos alimentos.

0 padrão de localização regional se rompe quando se analisam os fluxos de fornecimento de frutos, quando pela a participação ampla de áreas ao sul de Portugal, principalmente o Algarve: estabelece uma outra lógica espacial de insumos, denotando mudanças conforme o segmento em analise. A par dessa participação de quase todo territorio nacional, os estabelecimentos pesquisados também procuram algumas frutas, sobretudo as tropicais, em locais para além das fronteiras de Portugal, atraves de estabelecimento atacadista, a origem de algumas dessas frutas estão em paises do continente africano e sul-americano, com tradição na exportação para mercados europeus.

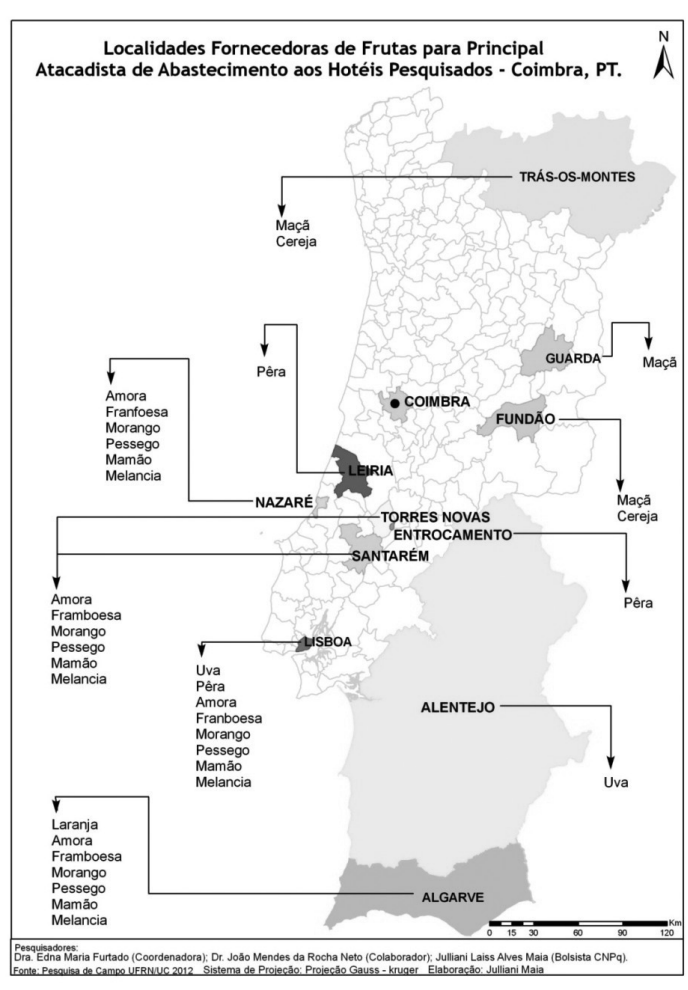

Figura 3

Localidades fornecedoras de frutas para os hotéis de Coimbra e Figueira da Foz

Fonte: Pesquisa de campo, 2013.

No que se refere aos equipamentos e utensilios utilizados pelos estabelecimentos, predomina a aquisição de bens nos atacadistas locais. Há também outro ponto convergente que sinaliza para o fornecimento/produção localizados em áreas industriais tradicionais de Portugal, como as cidades de Lisboa e do Porto.

Outro aspecto que aproxima os dois casos, está no facto de alguns bens serem adquiridos no exterior, uma vez que são as redes hoteleiras, que atuam em escala mundial, as compradoras de fornecedores, tambem globais. O mapa seguinte mostra a origem de alguns desses equipamentos pelos estabelecimentos pesquisados em Coimbra e Figueira da Foz, sobretudo aquilo que provem dos países industrializados. Alguns fornecem grande quantidade e diversidade de produtos, pois são sede de grandes corporações hoteleiras que adotam padronização de mobiliário e enxovais.

No entanto, essa rede de fornecimento não se limita a tais países e por vezes chega a alcançar áreas distantes, dependendo da relação custo-benefício, fato que se observa principalmente em relação aos eletroeletrônicos adquiridos junto aos principais estabelecimentos atacadistas. Em geral, tais produtos se originam de países em processo de industrialização, marcados pela forte competição de seus produtos no mercado internacional. 


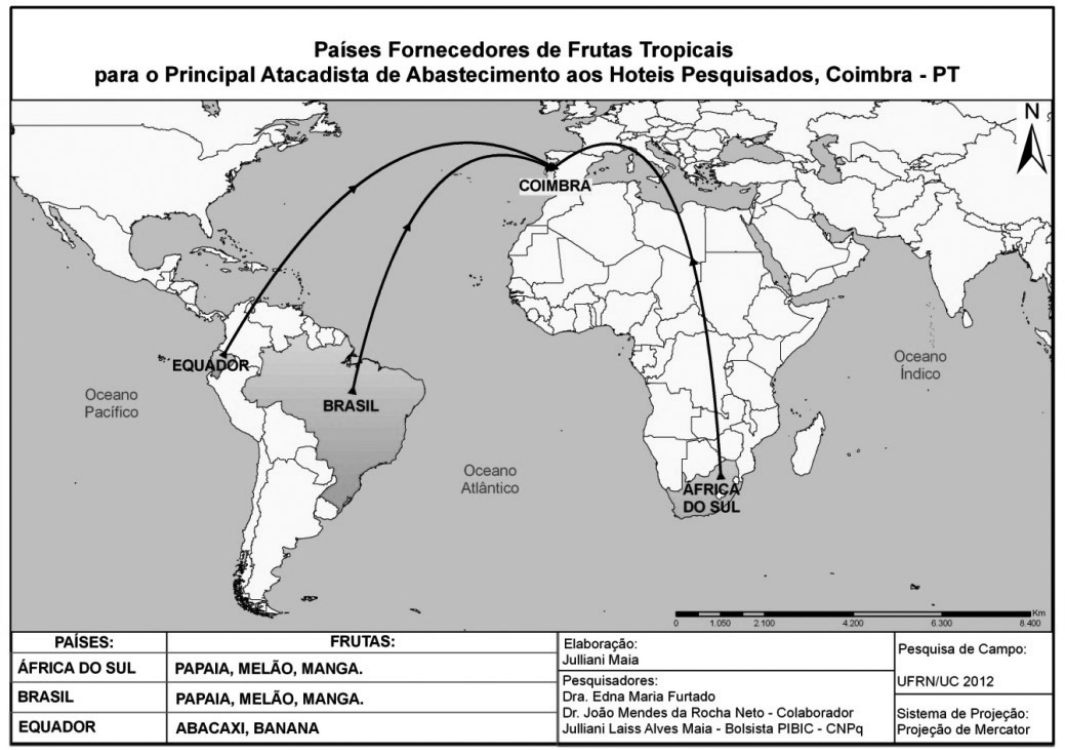

Figura 4

Localidades fornecedoras de frutas para os hotéis de Coimbra e Figueira da Foz Fonte: Pesquisa de campo, 2013.

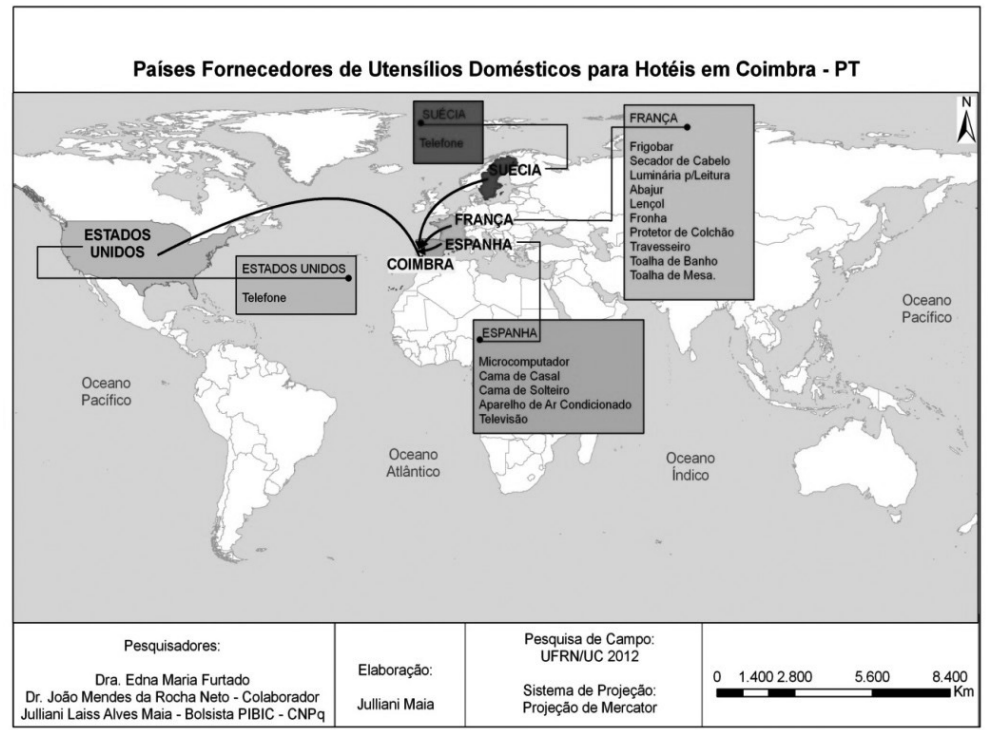

Figura 5

Localidades fornecedoras de utensilios domésticos para os hotéis de Coimbra.

Fonte: Pesquisa de campo, 2013

Os cartogramas se somam evidenciando que a lógica orientadora dos fluxos está pautada na maximização dos lucros, baseada na diminuição dos custos de operação. Para alguns estabelecimentos os valores desse conjunto de bens permanentes e dos produtos de consumo diário está associado à qualidade e continuidade de fornecimento, sustentando uma competitividade baseada no binômio preço-qualidade. Para alcançar esse status a rede de fornecimento tende a se espraiar por espaços além das fronteiras nacionais e muitas vezes chega a outros continentes, desde que ga- rantam níveis de lucratividade dos estabelecimentos hoteleiros.

Ressalte-se ainda, que há um conjunto de atividades acessórias, sobretudo de prestadores de serviços, relacionadas com esses fluxos de insumos de grandes estabelecimentos hoteleiros.

Tanto em Coimbra como em Figueira da Foz os serviços especializados, são geralmente contratados nos maiores centros, sobretudo nas cidades de Lisboa e do Porto.

Os dados apontam para algumas conclusões preliminares, mas sobretudo para a necessidade de 


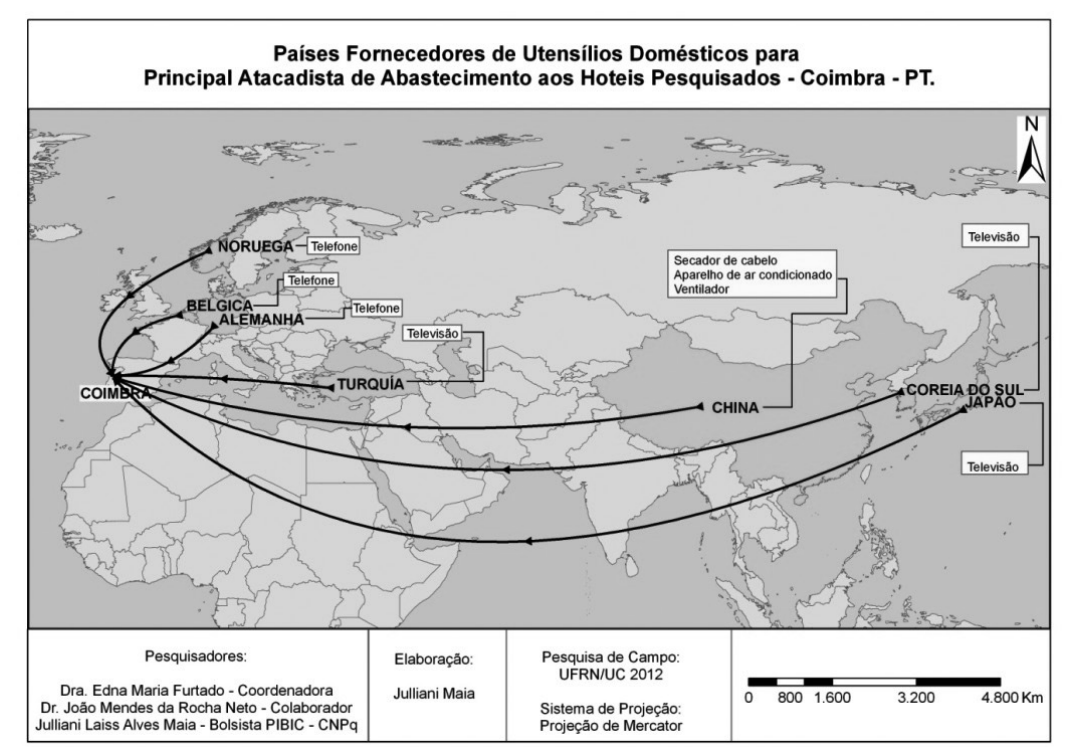

Figura 6

Origem dos utensílios domésticos para os atacadistas que abastecem os hotéis de Coimbra e Figueira da Foz Fonte: Pesquisa de campo, 2013.

um maior aprofundamento e qualificação das informações de modo a alcançar a complexidade do fenómeno que se pretende estudar. Assim, mais do que resultados, o artigo aponta para muitas outras possibilidades de investigação por cortes diversos, que podem ser por subsetores da atividade turística, ou por áreas geográficasfornecedores de insumos, partindo da metodologia construída e apresentada.

Nos casos estudados, percebeu-se que entre os grandes estabelecimentos há uma complexa rede que Ihes dá suporte. Acredita-se, ainda, que essa pesquisa pode responder ou aproximar algumas analises sobre as reestruturações territoriais em razão das novas dinâmicas econômicas que se relacionam tangencialmente com o turismo.

\section{Considerações finais: provocações para novos debates}

A pesquisa sobre a espacialidade turística apontou múltiplos meios para estudá-la, com recortes diversos a partir do porte dos estabelecimentos, da origem de seus fornecedores, além de outros perfis possíveis de serem delimitados. Essas distinções aparecem tanto quando se faz a segmentação por produtos, no caso dos insumos, como pela qualidade da força de trabalho.

No caso de Coimbra e Figueira da Foz, percebeu-se uma rede de insumos que varia menos tanto no tempo como no espaço, uma vez que as relações se dão entre fornecedores formalizados, via contratação, que por sua vez atendem aos padrões de qualidade dos estabelecimentos. No que se refere a mão de obra verifica-se uma considerável diferenciação nos locais de origem dos postos gerenciais, que representa uma maior capacitação dessa força de trabalho em âmbito local.
O turismo possui interfaces, disponibilizando inúmeras possibilidades de estudo e abordagens. Mas essa miríade de oportunidades de análise, levanta algumas vezes realidades à parte, ou seja, mostra somente um efeito produzido pela atividade turística, de forma localizada e não revela seus efeitos para as áreas que fornecem insumos para sua reprodução.

Analisar as atividades que complementam o turismo a partir da tessitura de uma rede de lugares evidencia um aspecto pouco estudado, tanto pela geografia como pelo turismo, ou mesmo pela economia. No caso especifico, verificou-se que para que os viajantes tenham suas necessidades elementares atendidas nos estabelecimentos hoteleiros, existe toda uma logística dando-lhes o devido apoio, onde inúmeras atividades de outros são criadas e desenvolvidas. O que neste estudo é o fim - "atividades sustentáculos" - para outros trabalhos pode representar o começo de uma pesquisa, reforçando ou não os entendimentos desse primeiro momento. Não se teve a pretensão de esgotar ou limitar o estudo do turismo em geografia, mas colaborar na discussão da metodologia utilizada com o desejo de aperfeiçoá-la, para cada vez mais desvendar essa atividade e suas relações no tempo e no espaço, reforçando o seu caráter multidisciplinar.

\section{Referências}

DiNIz, Luís Henrique Freitas e RALFO, Matos (2006) - "Distribuição e Funcionalidades espaciais do terciário moderno". Cadernos Metrópoles, $\mathrm{n}^{\circ} 16$, p. 59-83.

Barreto, Margarita (2003) - Turismo, políticas públicas e relações internacionais. Campinas: Papirus (Coleção Turismo). 
BENI, Mário (1998) - Análise estrutural do turismo. São Paulo, SENAC.

CravidÃo, Fernanda (2004) - "Turismo e cultura: o lugar dos lugares”. Revista Turismo Visão e Ação, Itajaí, UNIVALI,. Vol. 6, n³.

ETGES, Virgínia Elisabeta (1998) - Turismo rural: uma alternativa de desenvolvimento para comunidades rurais. In: LIMA, Luiz Cruz - Da cidade ao campo: a diversidade do saber-fazer turístico. Fortaleza, UECE.

Furtado, Edna Maria (2005) - A "onda" do turismo na cidade do sol: a reconfiguração urbana de Natal. Tese de Doutorado em Ciências Sociais - UFRN, CCHLA, Programa de pós-graduação em Ciências Sociais. Natal.

GÁrCIA, Fernanda Ester Sánchez (1998) - “Estratégias comunicacionais para o desenvolvimento do turismo urbano". In: LimA, Luiz Cruz - Da cidade ao campo: a diversidade do saber-fazer turístico. Fortaleza, UECE.

Nunes, Carlos Manuel de Freitas Almeida (2009) - Figueira da Foz (1930-1960): apontamentos sobre o Turismo Balnear. Dissertação de Mestrado. Coimbra.
OlivelRA, Antonio Pereira (2001) - Turismo e desenvolvimento: planejamento e organização. São Paulo, Atlas.

SAntos, Milton (1996) - Metamorfoses do espaço habitado. São Paulo, HUCITEC.

Santos, Norberto (2012) - "Cidade: Património e Espaço de vida”. In Passos, Messias M. dos; Cunha, Lúcio e Jacinto, Rui (org.) - As novas geografias dos países de língua portuguesa: paisagens, territórios e políticas no Brasil e em Portugal (II). São Paulo, Outras Expressões.

SıLvA, Jorge Antonio Santos (2004) - Turismo, crescimento e desenvolvimento: uma Análise Urbano-Regional baseada em clusters. Tese de Doutorado em Ciências da Comunicação, Universidade de São Paulo, São Paulo-SP, 468 p.

SIRGADO, José Rafael - Turismo nas regiões portuguesas: contributo para modelação de um cenário de desenvolvimento $e$ inovação para o final do século. Disponível em: http:// www.apgeo.pt/files/section44/1235567021_INFORGEO_06_ p021a036.pdf

UnIVERSIDADE de BRASília /CET (2008) - Impacto do turismo na economia do Distrito Federal. Brasília: SENAC. 